Supplement of Hydrol. Earth Syst. Sci., 23, 93-105, 2019

https://doi.org/10.5194/hess-23-93-2019-supplement

(c) Author(s) 2019. This work is distributed under

the Creative Commons Attribution 4.0 License.

(c) (1)

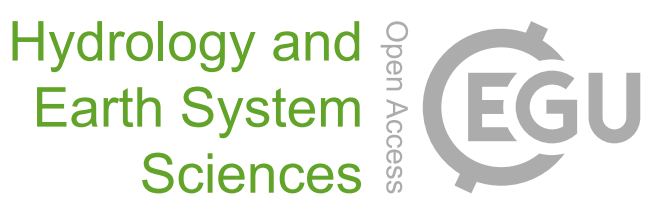

Supplement of

\title{
Exploring the use of underground gravity monitoring to evaluate radar estimates of heavy rainfall
}

Laurent Delobbe et al.

Correspondence to: Laurent Delobbe (laurent.delobbe@meteo.be)

The copyright of individual parts of the supplement might differ from the CC BY 4.0 License. 
The following figures show the gravity and radar time series for the 14 convective days as presented in Section 3 . Following time series are shown: residual gravity, radar reflectivity, radar rainfall rate and cumulative rainfall, not corrected for hail (red) and corrected with a hail threshold of $48 \mathrm{dBZ}$ (green).

The last figure is a scatter plot showing the rainfall amounts derived from radar and gravimeter measurements for 506 5 precipitation events with max reflectivity exceeding $40 \mathrm{dBZ}$. It is similar to Fig. 6 but (1) the conversion from reflectivity to rainrate is here based on the RADOLAN ZR relation and (2) a hail correction using a 48-dBZ threshold is applied. The best agreement between radar- and gravimeter-derived rainfall amounts is obtained using these settings. 

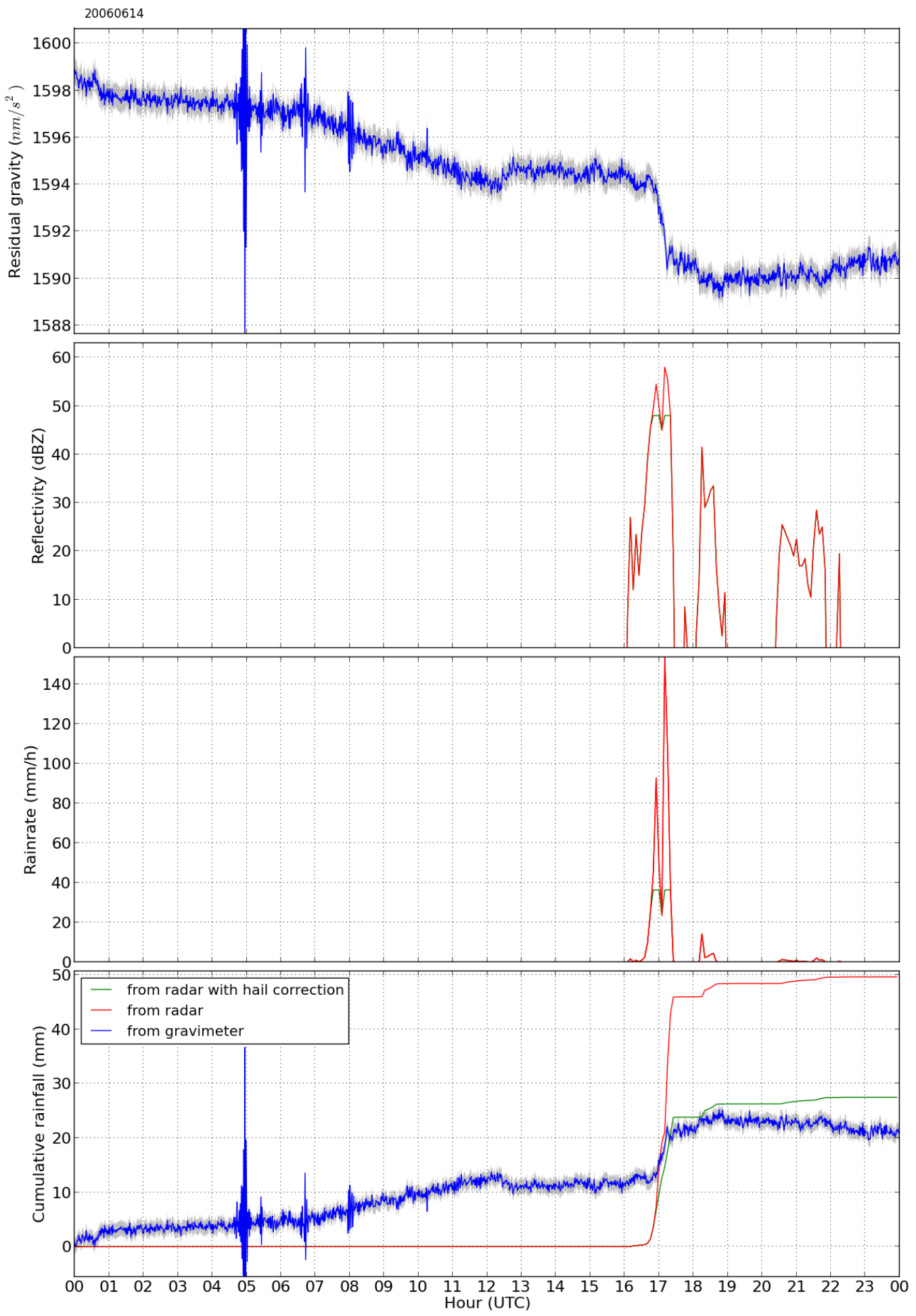

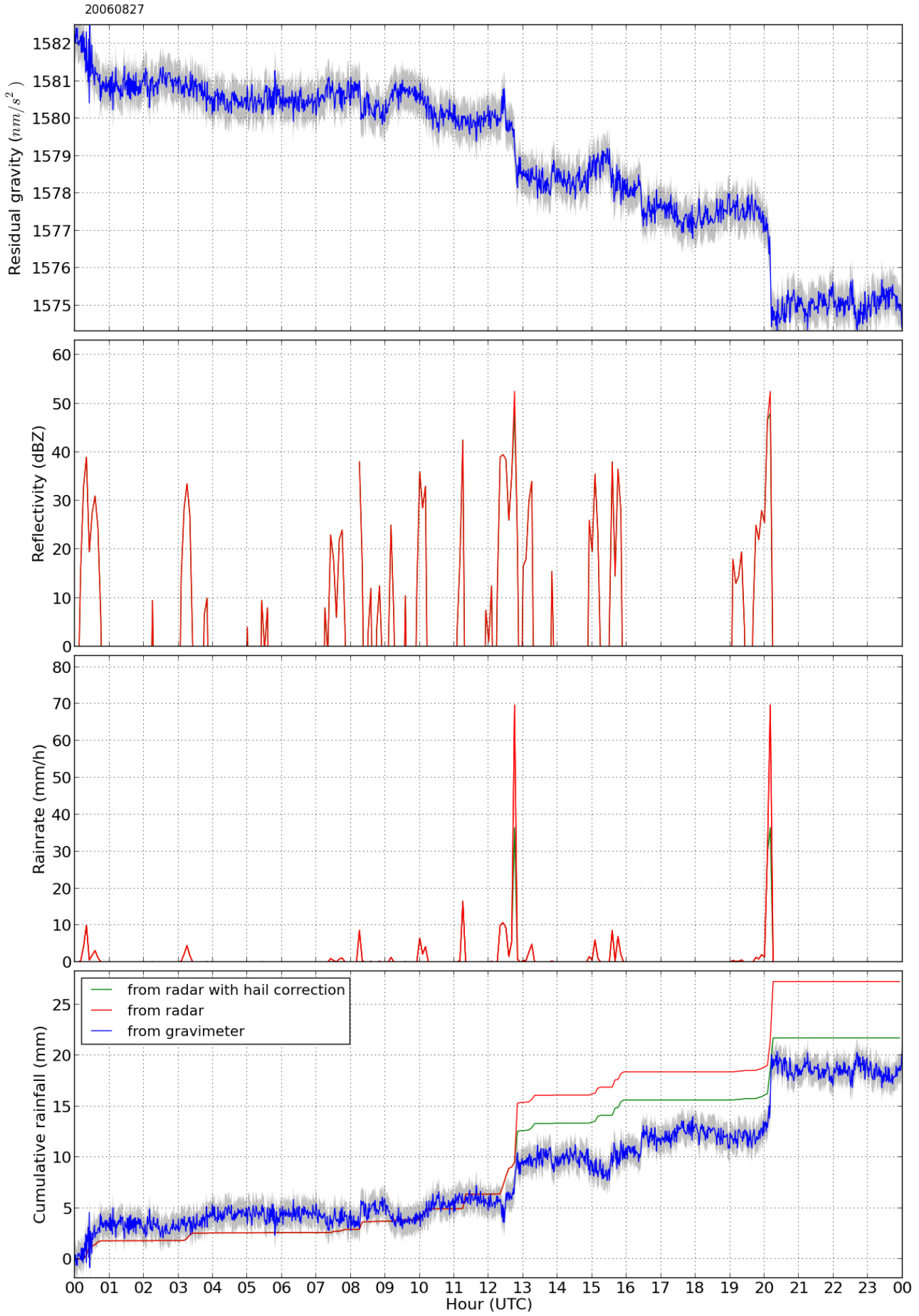

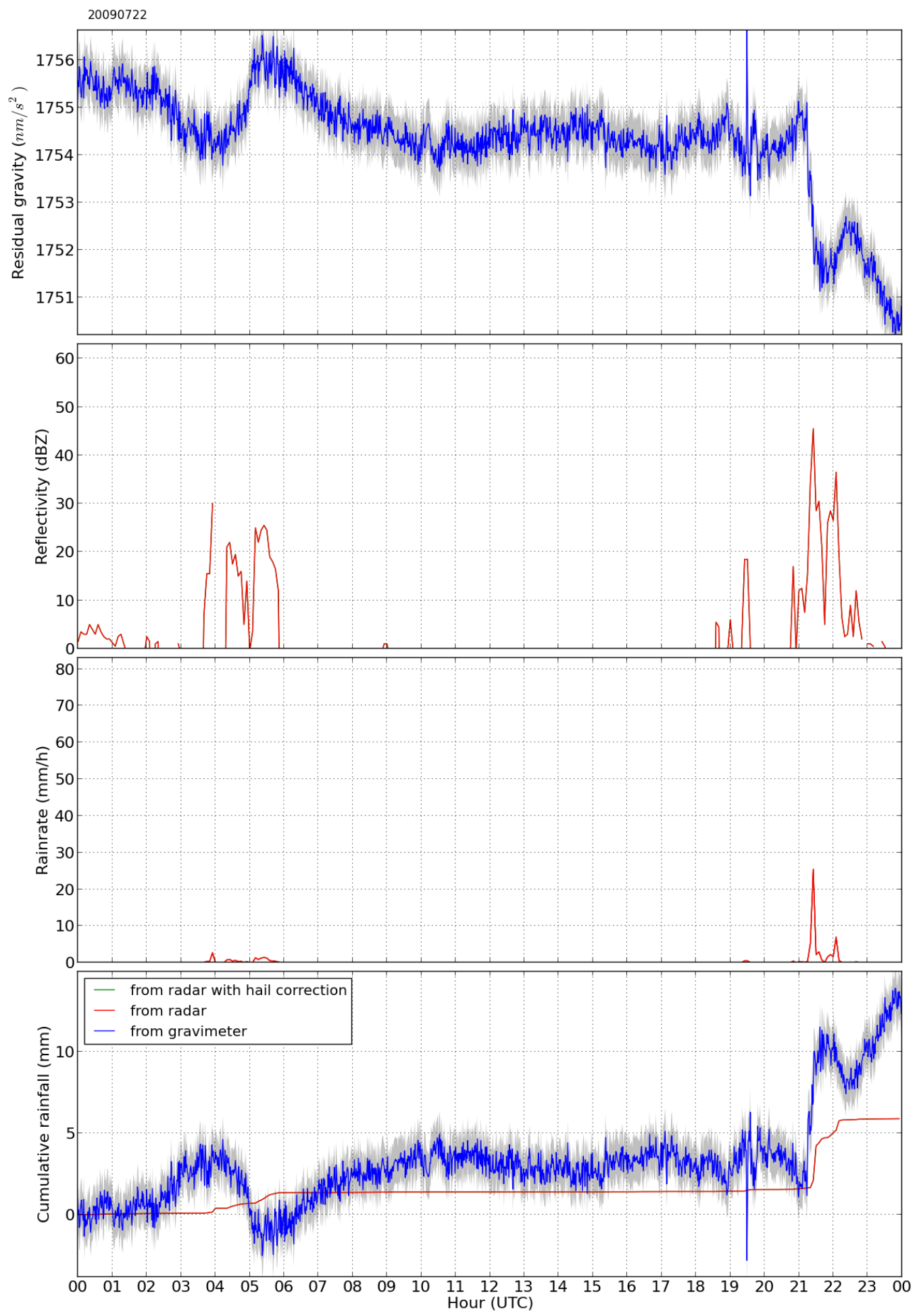

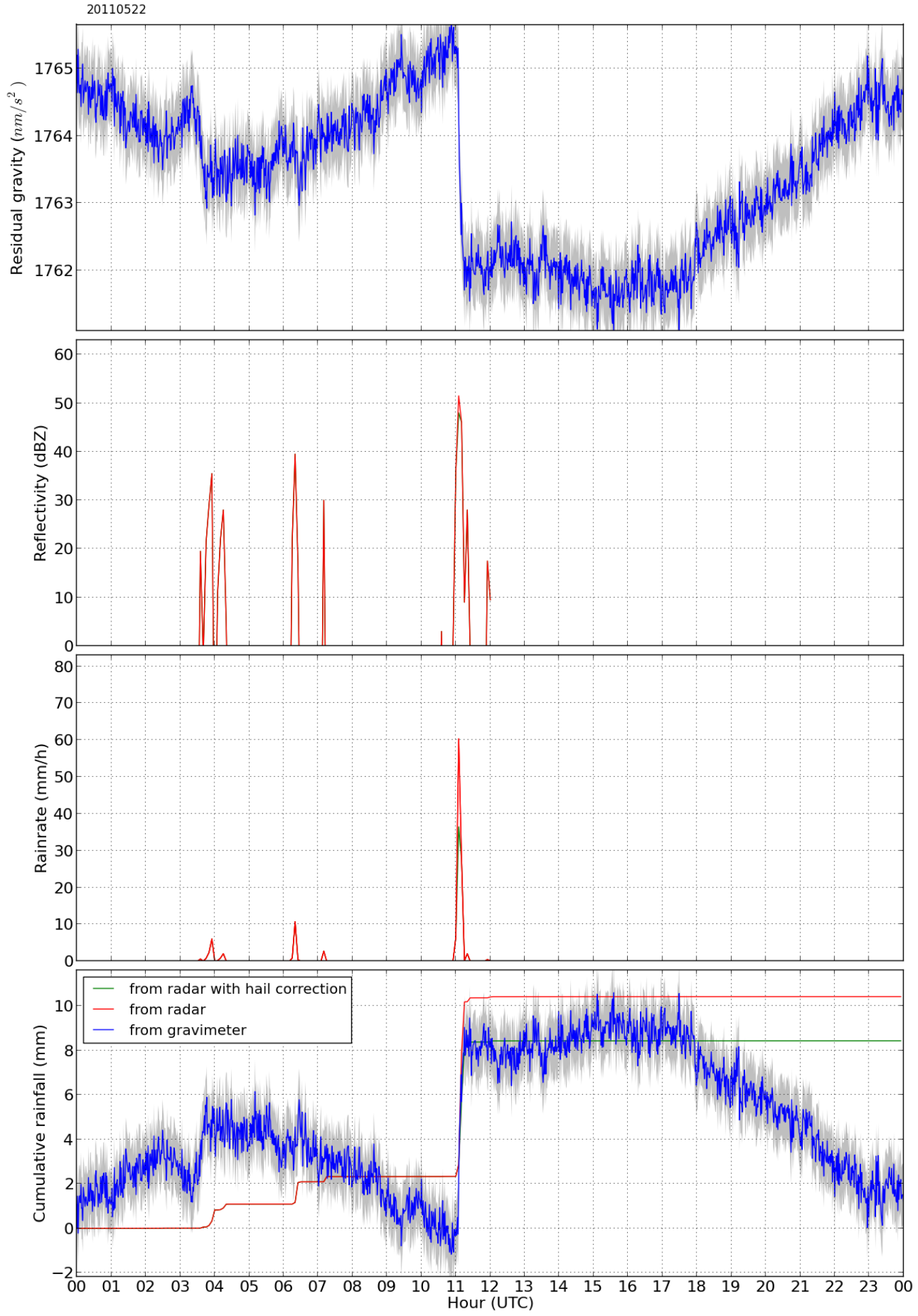

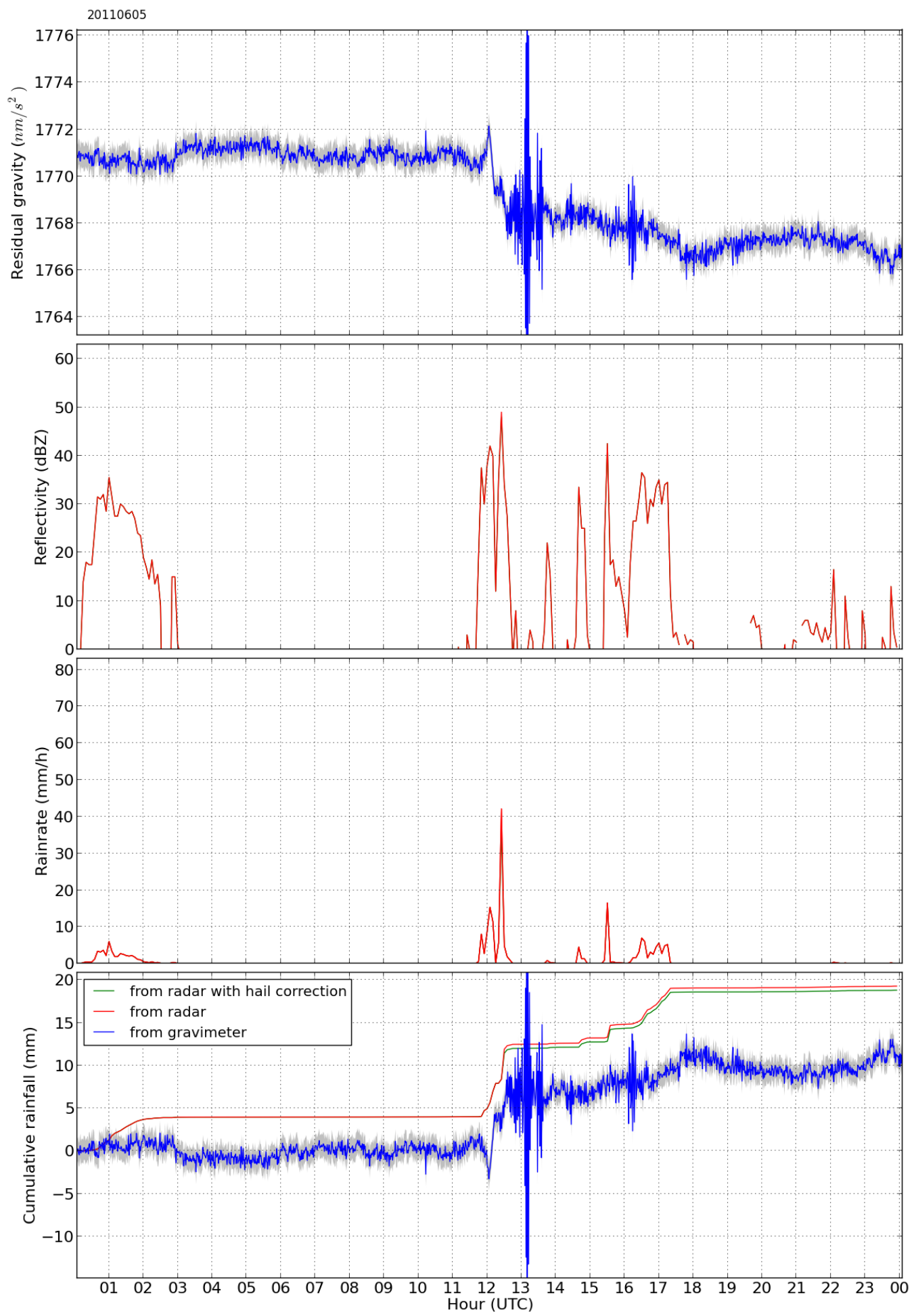

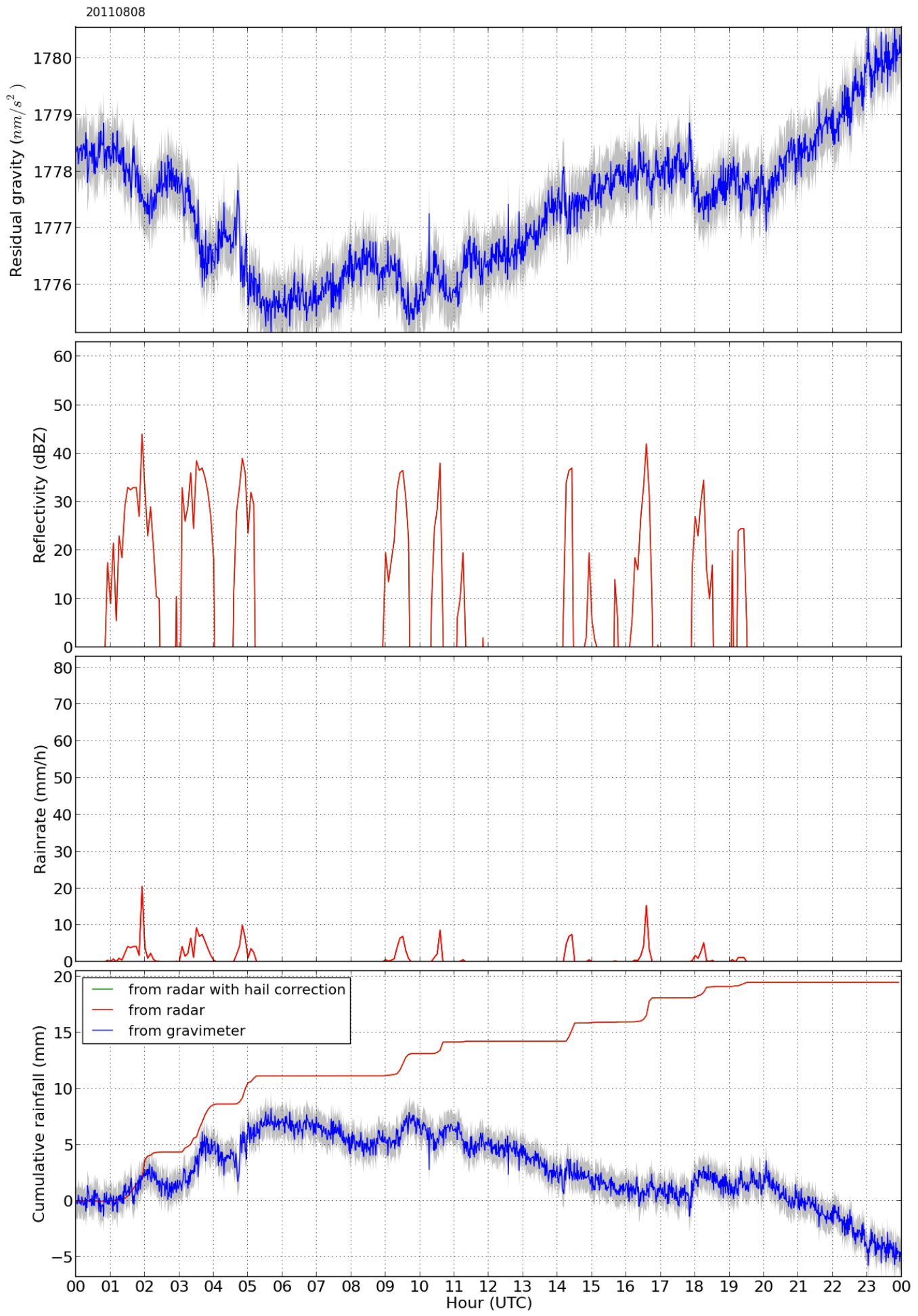

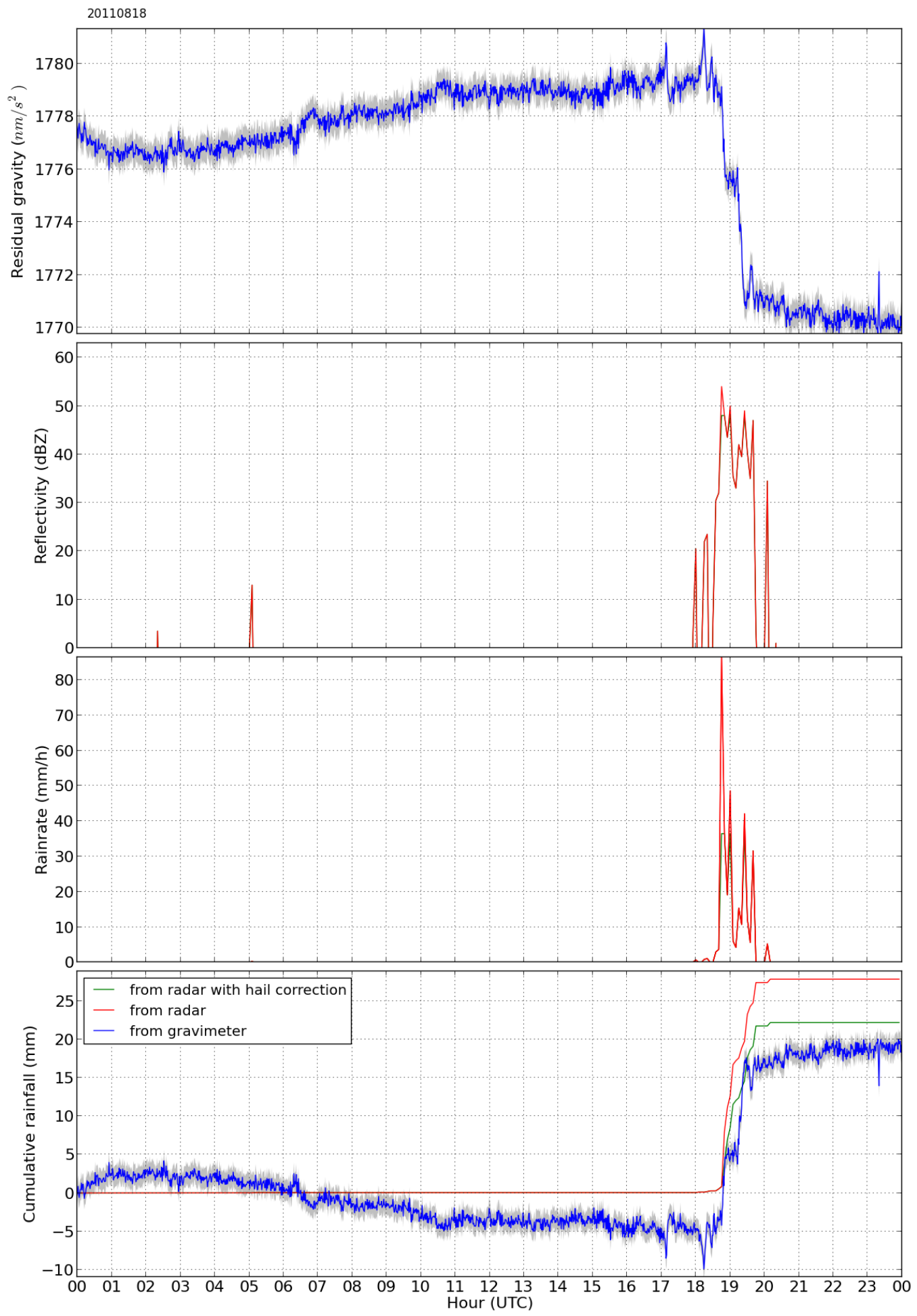

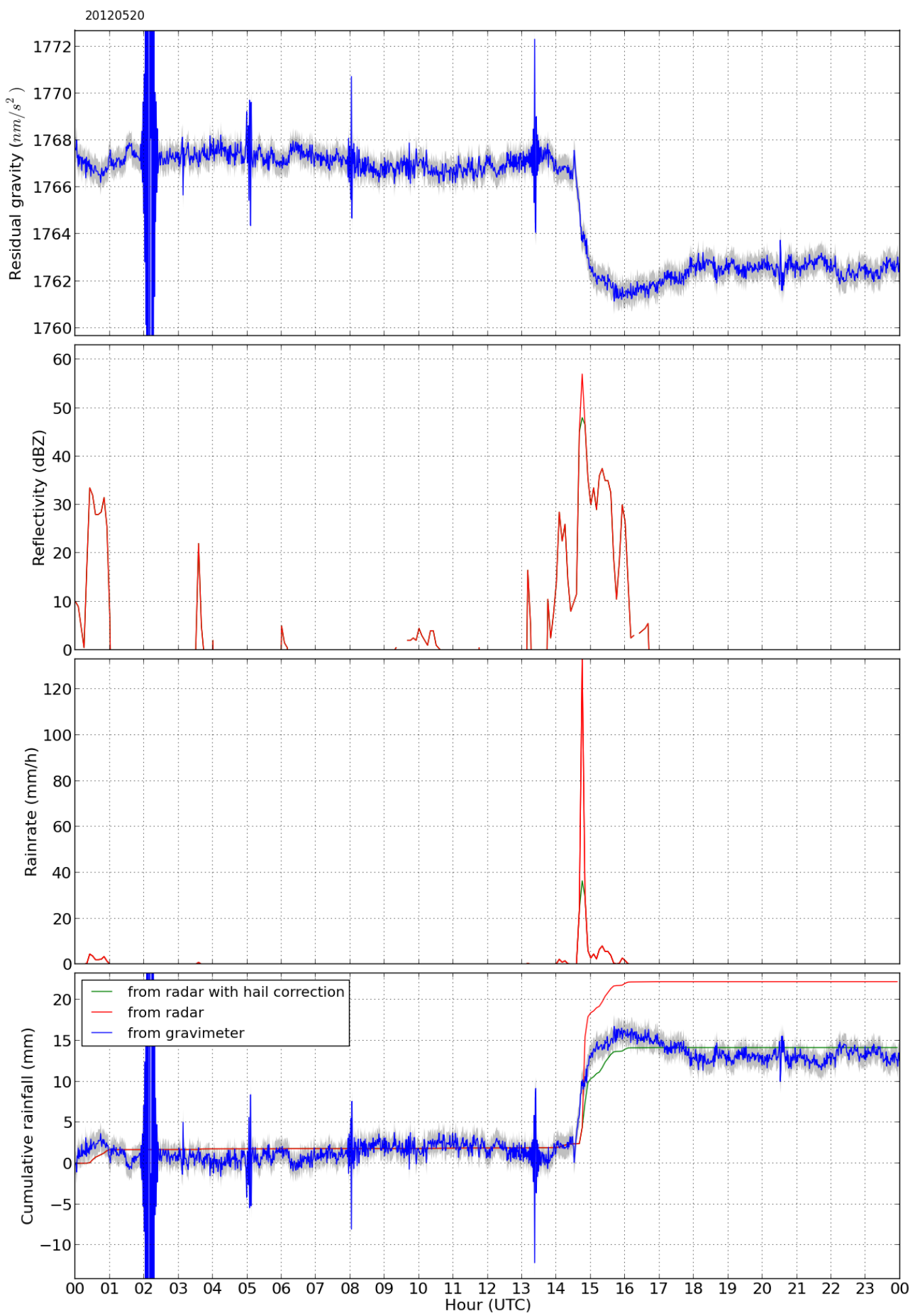

9 
20120728
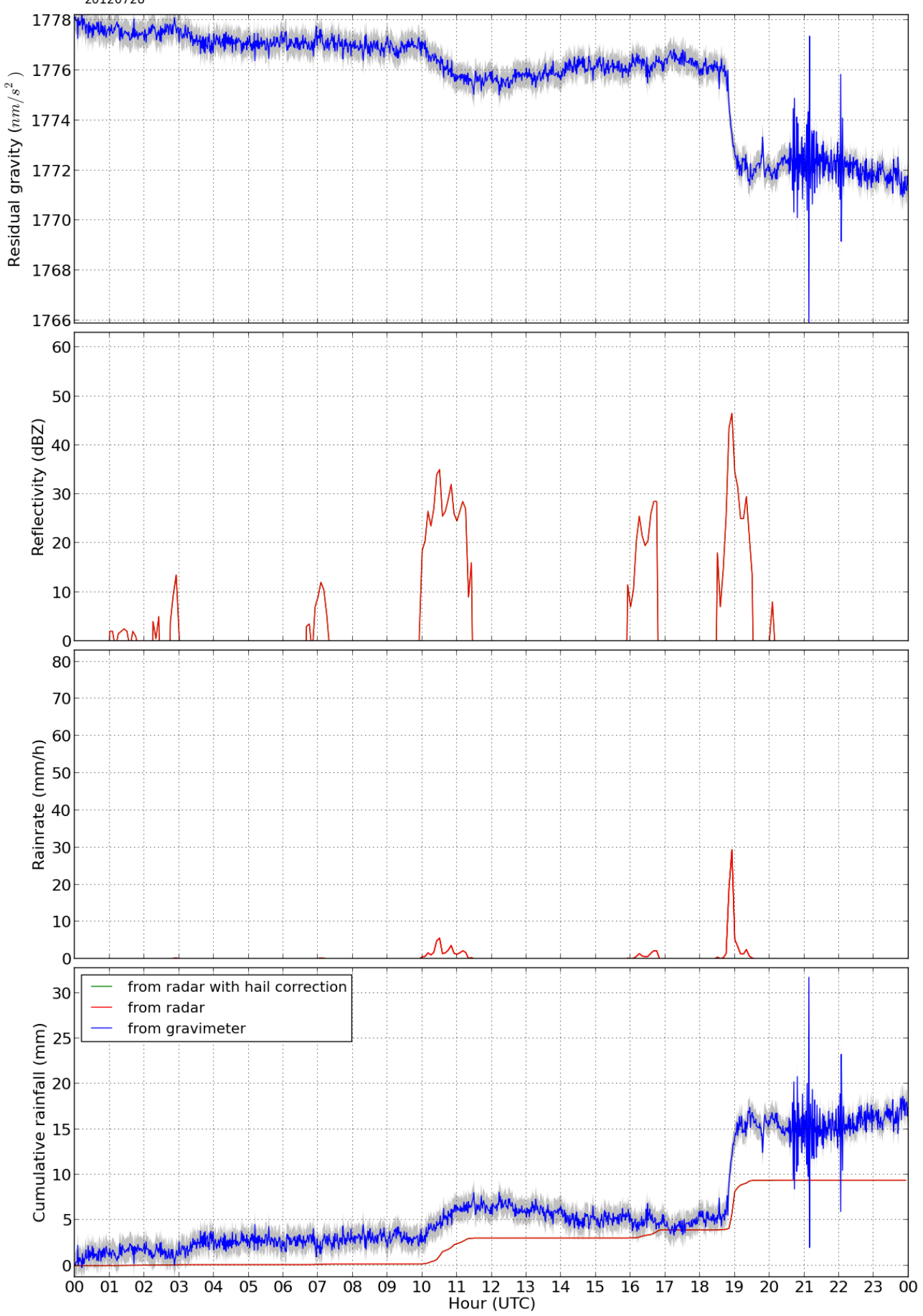

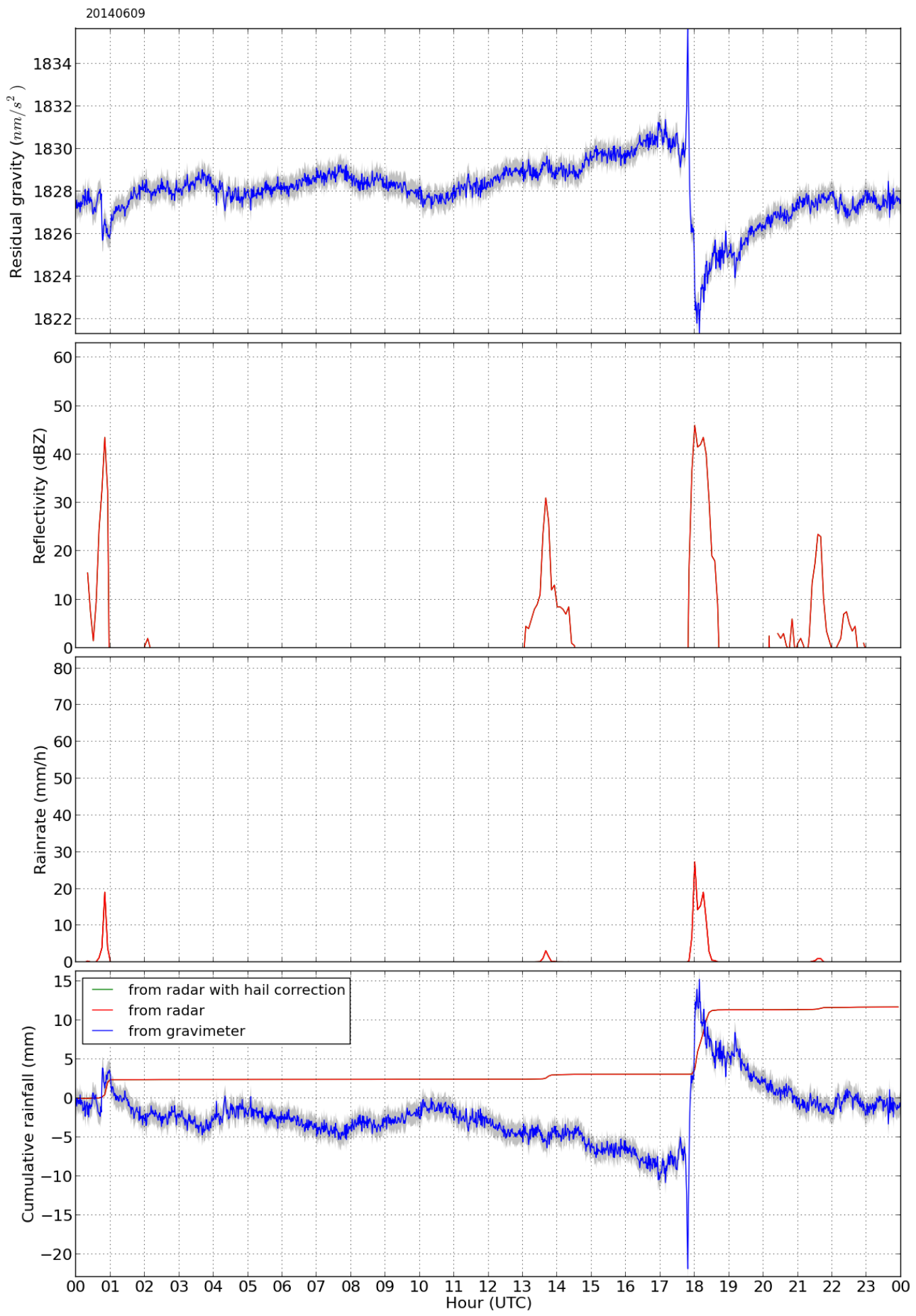

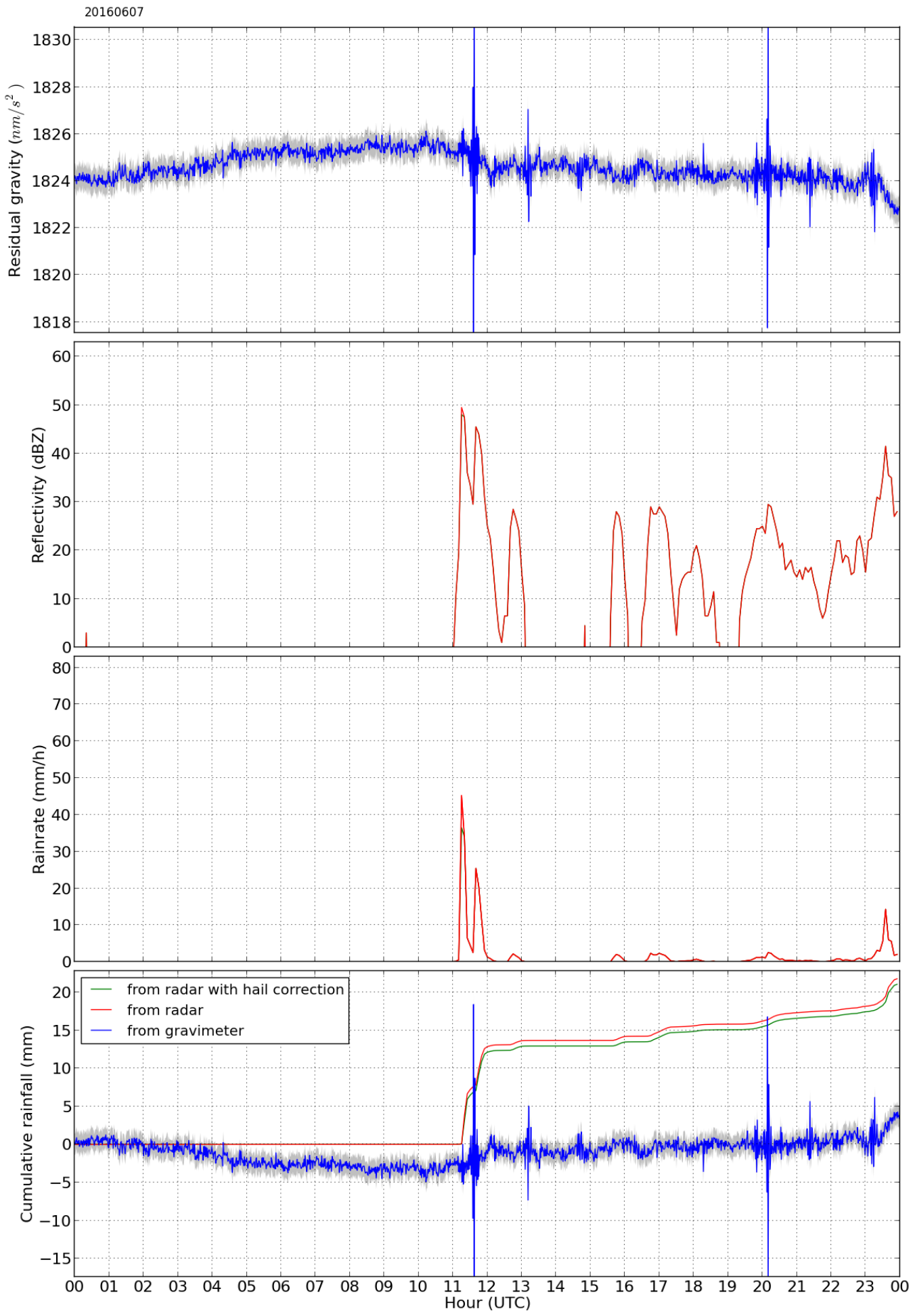

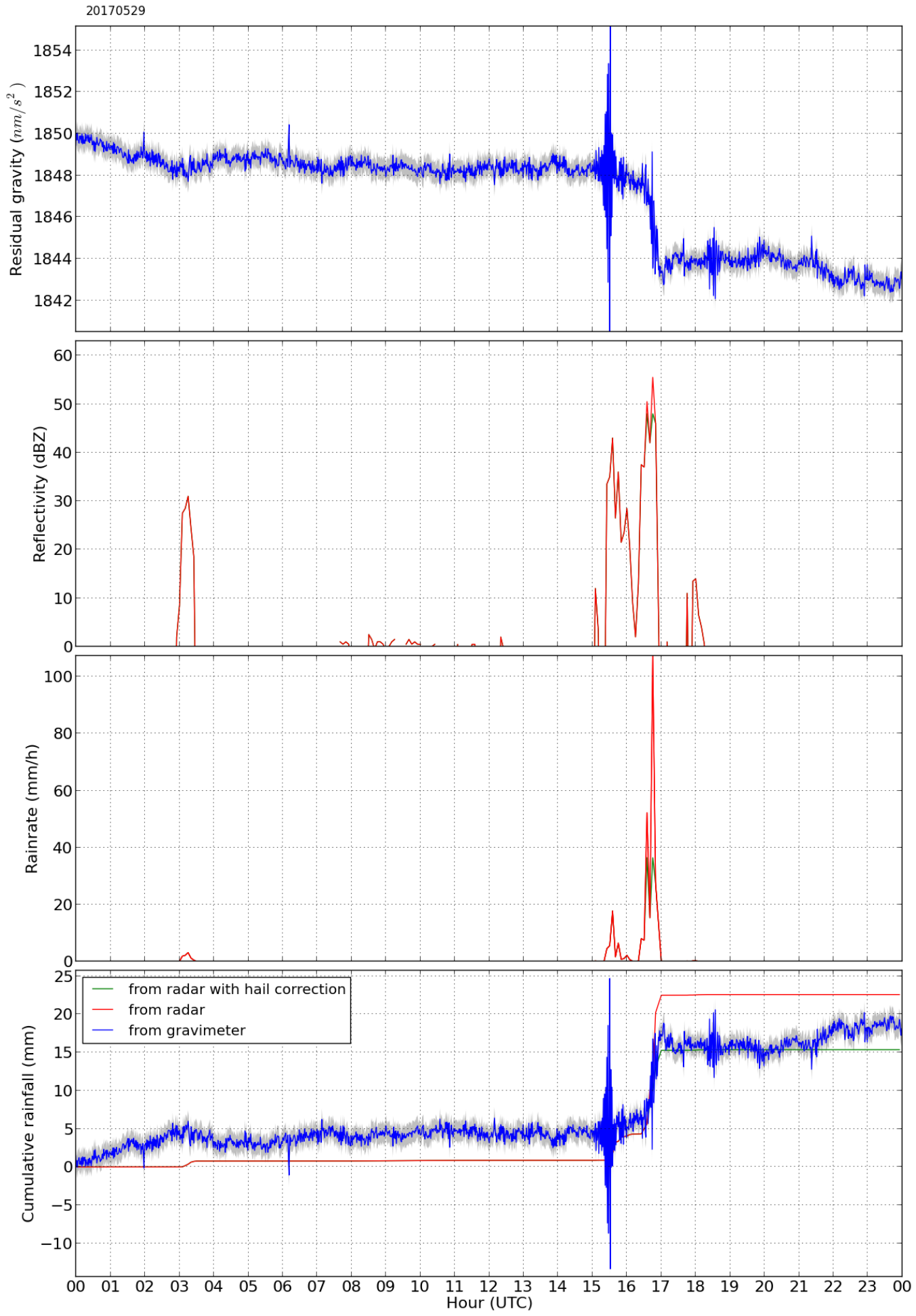

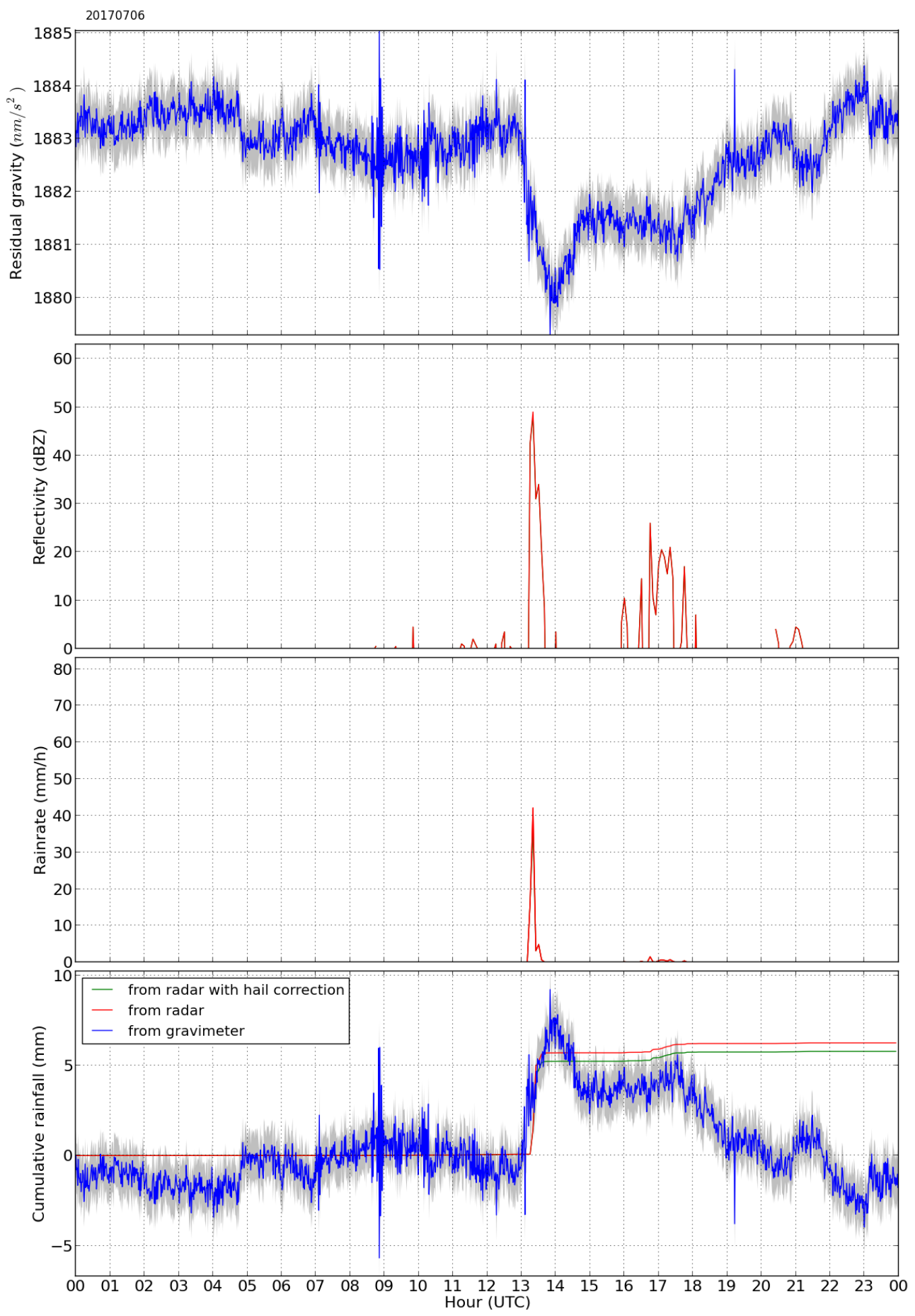

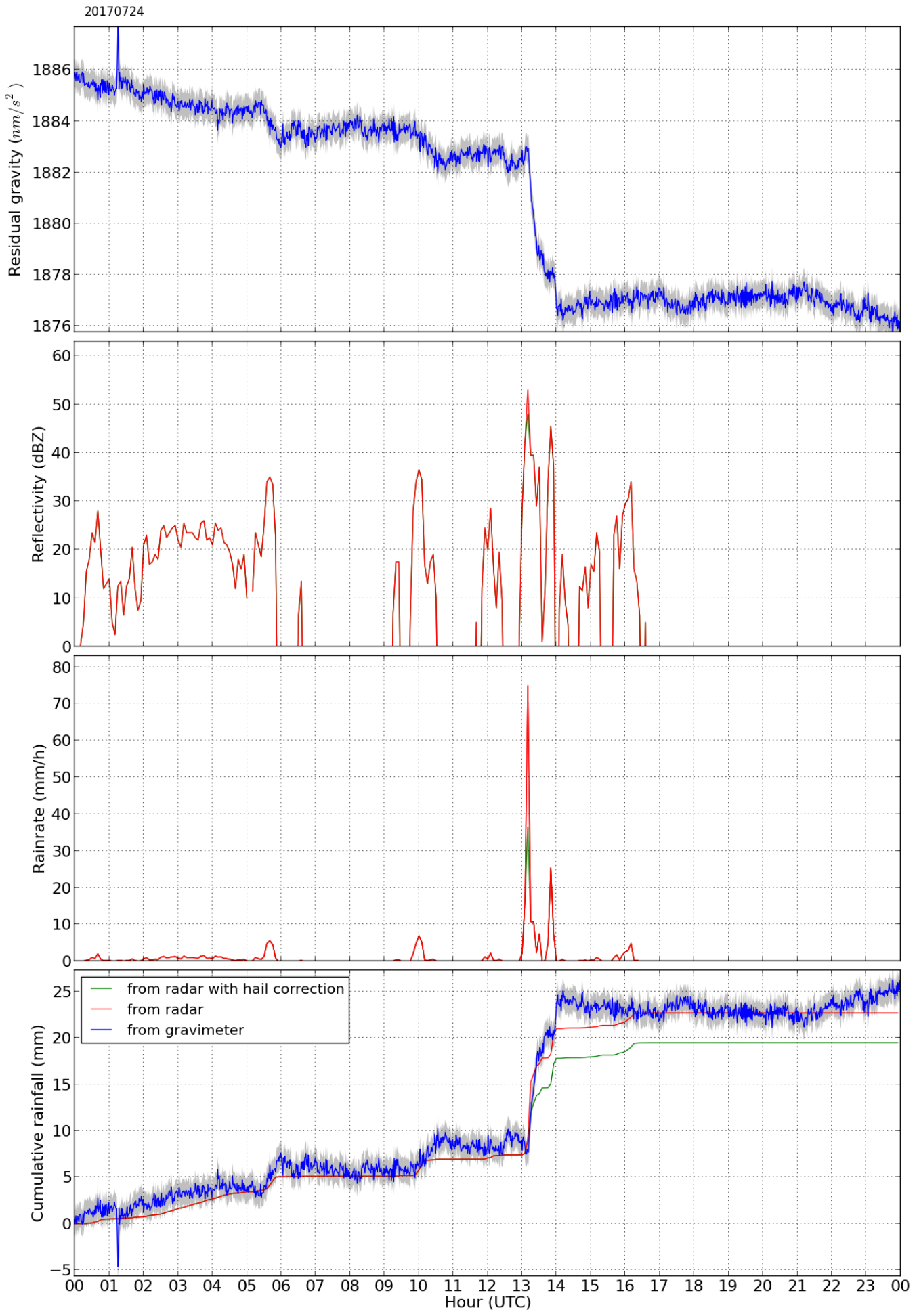


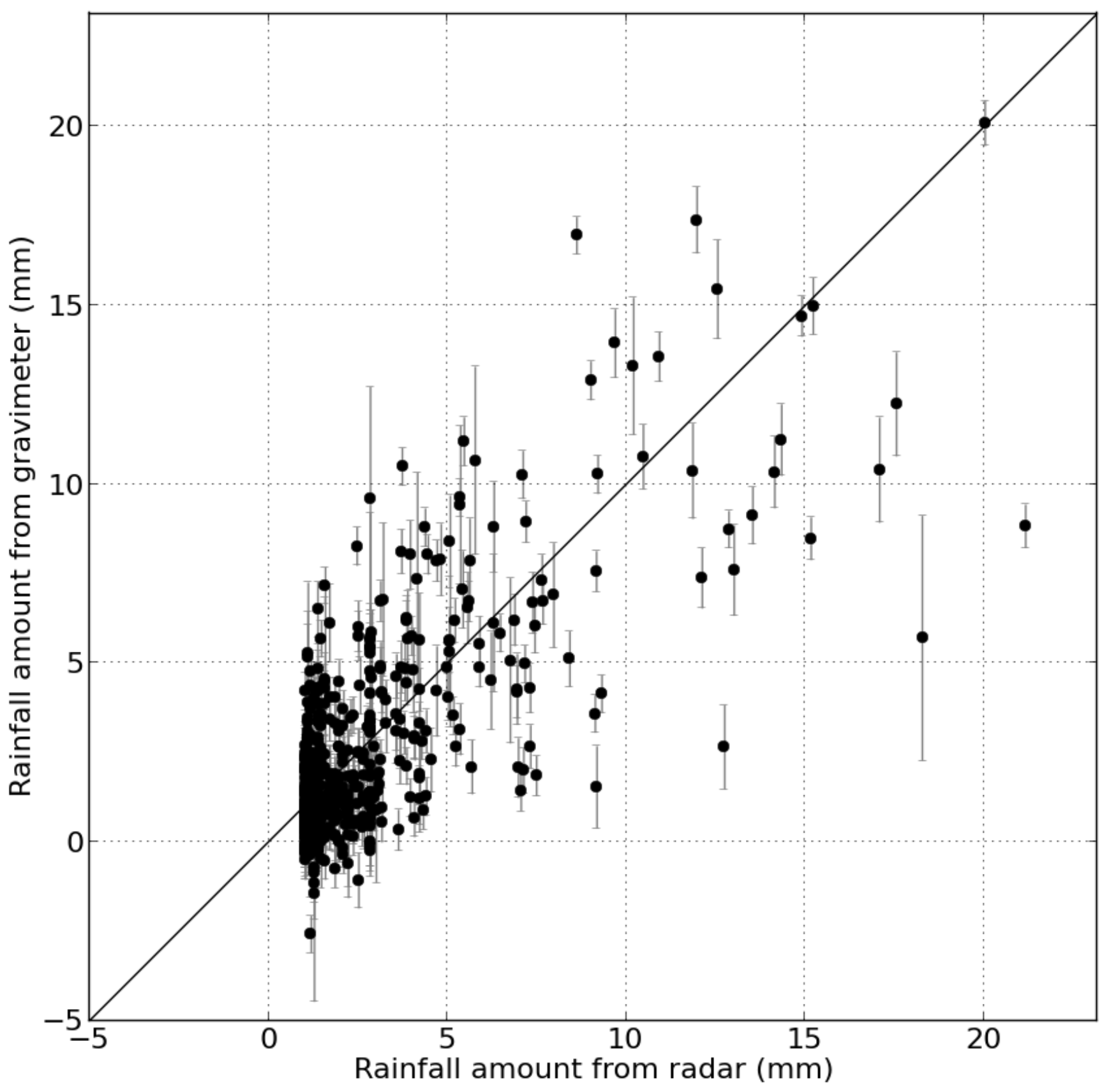

